\title{
LA DISTRIBUCIÓN DE COMPETENCIAS EN MATERIA TURÍSTICA EN LA REPÚBLICA ARGENTINA. ESPECIAL MENCIÓN A DESTINOS TURÍSTICOS DE RECIENTE DESARROLLO
}

\author{
EUGENIO DEL BUSTO ${ }^{1}$ \\ Profesor Adjunto de Introducción al Derecho y Política y Legislación Turística y Hotelera \\ Departamento de Economía y Administración \\ Universidad Nacional de Quilmes \\ Buenos Aires (Argentina)
}

\section{Resumen}

El objetivo del presente artículo es realizar un estudio de la distribución de competencias en materia turística entre la nación, las provincias y los municipios en Argentina, enfatizando su análisis en destinos turísticos de reciente desarrollo. Concluye en la necesidad de otorgar mayores competencias normativas a los municipios turísticos, para favorecer su desarrollo.

Palabras clave: Turismo - Derecho - Distribución de competencias - Legislación Municipios turísticos

\section{Abstract}

The aim of this paper is to achieve a study about the distribution of tourism competencies among the nation, provinces and municipalities in Argentina, emphasizing their analysis in recently developed tourists destinations. Concludes in the need to grant greater regulatory powers to tourism municipalities to promote their development.

Key words: Tourism - Law - Distribution of competences - Legislation - Tourist municipalities

\section{INTRODUCCIÓN}

Una de las consecuencias que ha traído aparejado el aumento del tiempo libre destinado al ocio, es que ha provocado un progresivo y permanente fortalecimiento, entre otras, de la actividad turística. Ese impulso se basa fundamentalmente en los avances en materia de política laboral hacia finales de la primera mitad del siglo pasado -en particular respecto de salarios, vacaciones pagas, descanso semanal, entre otros-; que fueron

\footnotetext{
1 edelb@uvq.edu.ar

El presente trabajo se enmarca en el "Programa Dimensiones y alcances del desarrollo territorial". Proyecto "Destinos turísticos de reciente desarrollo en la República Argentina. Estudios de casos y aportes teóricos" de la Universidad Nacional de Quilmes - Departamento de Economía y Administración, desarrollado entre mayo 2011y abril 2015 en el que participara el autor como Investigador, así como en la indagación desarrollada respecto de otros destinos turísticos de reciente desarrollo.
} 
acompañados por la mejora de las comunicaciones y la infraestructura de transporte. Así se ha afirmado que las nuevas condiciones laborales promueven una ampliación social del turismo al generar las condiciones materiales y legales que institucionalizan la actividad como un derecho universal ${ }^{2}$. A raíz de ello, en la actualidad, puede afirmarse que el turismo se caracteriza por su generalización, es decir, por el ejercicio masivo y la democratización en su práctica, además de la extensión a diversos grupos sociales y la diversificación de comportamientos ${ }^{3}$.

En no pocas naciones el turismo se ha constituido en una de las principales fuentes de sostenimiento de su economía, destacándose entre sus efectos positivos la función multiplicadora y distributiva de la riqueza, la generación de empleo y su incidencia en la balanza comercial. A la trascendencia que ha cobrado ha de sumarse su papel como promotor de los procesos de desarrollo regional y local ${ }^{4}$, el rol que tiene en la dinamización de los destinos y en su crecimiento económico. Pero también presenta externalidades no deseadas como la modificación del valor inmobiliario del suelo, la inflación ${ }^{5}$, el impacto sociocultural y ambiental.

La importancia que el turismo ha adquirido es tal que ha llegado a afirmarse que se está en presencia de un derecho, tratamiento que le otorga el Código Ético Mundial para el Turismo ${ }^{6}$. Así se ha afirmado que el turismo transformado en derecho para un sector cada vez más creciente de la población, pasó a ser considerado no como un lujo sino como una necesidad ${ }^{7}$. Y hasta se ha sostenido que la posibilidad de viajar (de entrar, permanecer y salir de un territorio) constituye un verdadero derecho natural de la persona ${ }^{8}$.

La Ley Nacional 25997, de Turismo de la República Argentina, cuenta entre sus principios rectores -a cuya luz deben ser interpretadas sus disposiciones, y cualquier programa, proyecto o acción realizada en el marco de su regulación- al desarrollo social, económico y cultural, consagrando al turismo como un derecho social y económico de las personas 9 .

Como consecuencia de ello no puede dejar de afirmarse el trascendente rol que cabe al ordenamiento jurídico como herramienta para hacer efectivo el ejercicio de derecho antes

\footnotetext{
${ }^{2}$ SCHENKEL E. Política Turística y turismo social. Buenos Aires: Ediciones CICCUS, 2017, p. 92.

3 VERA, F. (Coordinador), LÓPEZ PALOMEQUE F., MARCHENA M.J., ANTÓN, S. Análisis Territorial del Turismo. Una nueva geografia del turismo. Barcelona: Editorial Ariel S.A., 1997, p. 18.

${ }^{4}$ CONSEJO FEDERAL DE INVERSIONES. Encuentro Federal de desarrollo local: el turismo como oportunidad de desarrollo. Conferencias y presentación de casos por expositores de Argentina, América y Europa. Buenos Aires: Consejo Federal de Inversiones, 2011, p. 8.

${ }^{5}$ BIGNE ALCAÑIZ, E., FONT AULET, X. y ANDREU SIMÓ, L. Marketing de destinos turísticos. Análisis y estrategias de desarrollo. Madrid: Editorial ESIC, 2000, p. 458.

${ }^{6}$ RESOLUCIÓN 56/212 adoptada por la Asamblea General de las Naciones Unidas el 21 de diciembre de 2001, Código Ético Mundial para el turismo.

${ }^{7}$ OBSERVATORIO DE POLÍTICAS PÚBLICAS DEL CUERPO DE ADMINISTRADORES GUBERNAMENTALES. El turismo como política de estado en la República Argentina, Buenos Aires: Jefatura de Gabinetes de Ministros, 2005, p. 7

${ }^{8}$ PÉREZ GUERRA R. Y CEBALLOS MARTÍN, Mª.M. La configuración del Derecho del Turismo Autonómico Español en el ordenamiento jurídico administrativo-constitucional En Revista Aragonesa de Administración Pública, núm. 35, Zaragoza, 2009, p. 455.

9 SECTUR. Ley Nacional de Turismo 25997. El comienzo del cambio. Buenos Aires: Secretaría de Turismo de la Nación, 2005, p. 9.
} 
enunciado, pero también ha de analizarse el papel que le corresponde en la potenciación del desarrollo turístico.

En tal sentido este artículo aborda en primer lugar el análisis de la distribución de competencias en materia turística en la República Argentina, entre los diferentes entes que tienen incidencia directa o indirectamente sobre ella, a fin de determinar sus potestades y las respectivas limitaciones.

Luego focaliza el estudio en diferentes municipios turísticos de reciente desarrollo y en las provincias argentinas en las que estos se sitúan, determinando en cada caso cuales son las potestades con las que cuentan, procurando identificar las materias respecto de las que poseen competencias y su impacto en la actividad turística.

Finalmente se efectúan algunas consideraciones sobre la necesidad de otorgar mayores competencias a los municipios analizados, con la finalidad de fortalecer el incipiente estadio de desarrollo turístico en el que se encuentran.

\section{LA DISTRIBUCIÓN DE COMPETENCIAS EN MATERIA TURÍSTICA EN LA REPÚBLICA ARGENTINA}

El estudio del turismo desde la perspectiva jurídica aborda la singularidad que la actividad presenta, en particular su carácter multidisciplinar y transversal, al igual que su complementariedad con diferentes sectores, lo que explica que un sinnúmero de medidas tengan de manera directa o indirecta impacto en esta materia ${ }^{10}$.

El análisis del subsistema jurídico del turismo es complejo, pero imprescindible para la indagación de cualquier política turística, que exige conocer la normativa que la sustenta, el conocimiento de los instrumentos legales que la soportan ${ }^{11}$.

Este carácter complejo que presenta el turismo y su vinculación con el derecho ya ha sido advertido al señalarse que el turismo es un fenómeno complejo, en el que un cúmulo de intereses y factores de las más variadas características confluyen en él, haciéndolo sin duda un interesante objeto de estudio, tanto desde el punto de vista económico como jurídico ${ }^{12}$.

La enunciada complejidad, aplicada a los tres niveles del Estado federal argentino: nacional, provincial y municipal, cada uno con competencias propias en materia turística, a los que se ha incorporado a partir de la reforma constitucional de 1994 la Ciudad Autónoma de Buenos Aires, da como resultado un amplísimo marco normativo conformado por un sinnúmero de leyes, decretos, reglamentos, resoluciones, disposiciones, con un alto grado de

\footnotetext{
${ }^{10}$ RODRÍGUEZ ARANA MUÑOZ, J. La distribución de competencias en materia de turismo, En Documentación administrativa 259-260, Enero-Agosto de 2001 Administración Pública y Turismo. Madrid: Instituto Nacional de la Administración Pública, 2001, p. 35.

${ }^{11}$ PEÑA MIRANDA, D. Los instrumentos legales de la política turística como base para un turismo responsable y sostenible en Latinoamérica; análisis para Colombia, Perú, México y Honduras, En Revista de Análisis Turístico $N^{o} 8,2^{\circ}$ semestre 2009. Asociación Española de Expertos Científicos en Turismo, 2009, p. 34, disponible en: http://www.aecit.org/jornal/index.php/AECIT/article/view/76

12 ARCARONS SIMONS, R. Manual de Derecho Administrativo Turístico, Madrid: Editorial Síntesis, 1999, p. 40.
} 
dispersión. Puede ser ésta una de las causas por las que sólo en las últimas décadas, se haya acometido su estudio por parte de la doctrina argentina, al menos desde la perspectiva del derecho público.

El estudio de la distribución de competencias turísticas, en lo que respecta a la literatura jurídica en España es amplio y puede advierte su tratamiento en obras generales de Derecho del Turismo ${ }^{13}$, en artículos que hacen referencia a la distribución de competencias turísticas $^{14}$ a las competencias de las Comunidades Autónomas ${ }^{15}$ y también a las correspondientes a los municipios turísticos ${ }^{16}$.

Puede sostenerse que el abordaje específico del reparto de competencias en turismo, por parte de estudiosos del campo, se encuentra en pleno proceso de desarrollo. Sin embargo, no menos cierto es que para su análisis se cuenta con una base sólida en obras jurídicas de derecho constitucional ${ }^{17}$; relativas al derecho público provincial $^{18}$ y al derecho público

13 FERNÁNDEZ RAMOS, S. (Dir.) y PÉREZ GUERRA, R. (Coord.) Manual de Derecho Administrativo del sector turístico, Tecnos, Madrid, 2013; FERNÁNDEZ RODRÍGUEZ, C. Derecho Administrativo del turismo (Quinta Edición), Barcelona: Marcial Pons, 2010; FONT I LLOVENT, T. Y VANDELLI, L. (Dirs.). Ordenación jurídico-administrativa del turismo. Barcelona: Atelier; PÉREZ GUERRA, R. (Dir.) Derecho de las actividades turísticas, Barcelona: Fundación Universidad Oberta de Cataluña UOC, 2003.

${ }^{14}$ GALlardo CASTILlO, M. J. La distribución constitucional de competencias en materia de turismo y su tratamiento en las Leyes Autonómicas: su promoción y su ordenación. En Documentación Administrativa 259-260, Administración Pública y Turismo. Madrid: Instituto Nacional de la Administración Pública, 2001; GUILLEN GALINDO, M. La distribución de competencias entre el Estado, las Comunidades Autónomas y las Entidades Locales. Especial referencia a la Comunidad Valenciana, En Actas del I Congreso Universitario de Turismo, celebrado los días 27 a 29 de Octubre de 1998 en Peñíscola, Castellón. Valencia: Tirant lo Blanch, 1999; MATA IZQUIERDO, J. Turismo, En Derecho público y administración de la Comunidad de Madrid, Madrid: IMAP; RODRÍGUEZ ARANA MUÑOZ, J. La distribución de competencias en materia de turismo. En Documentación Administrativa 259-260, Administración Pública y Turismo. Madrid: Instituto Nacional de la Administración Pública, 2001.

${ }^{15}$ CEBALlOS MARTÍN, Mª M., PÉREZ GUERRA, R. y DEL BUSTO, E. La legislación o derecho del turismo. Especial referencia a la Comunidad Autónoma de Andalucía, Congreso Universitario Internacional sobre turismo en Andalucía y norte de Marruecos: nuevos retos, nuevas propuestas, Universidad de Málaga, Málaga, 23 y 24 de Octubre de 2014, Málaga: Facultad de Turismo de la Universidad de Málaga, 2014; FERNÁNDEZ ÁLVAREZ, Competencias en materia turística de la Comunidades Autónomas, Revista Estudios Turísticos $N^{o}$ 85, 1985, pp. 37-46; GALERA VICTORIA, A. Turismo en F. Balaguer Callejón (Director) Reformas Estatutarias y Distribución de Competencias, Sevilla: Instituto Andaluz de Administración Pública, 2007; PÉREZ GUERRA, R. y CEBALLOS MARTÍN, Mª . M. Las competencias de la comunidad autónoma de Andalucía en materia de turismo, en Severiano Fernández Ramos (coord.) Estudios sobre derecho andaluz del turismo, Consejería de Turismo, Comercio y Deporte, de la Junta de Andalucía, Sevilla: 2008, pp. 23 a 64.

${ }_{16}$ BERMEJO VERA, J. Régimen jurídico de los municipios turísticos, En En Documentación Administrativa 259-260, Administración Pública y Turismo. Madrid: Instituto Nacional de la Administración Pública, 2001; PÉREZ GUERRA, R, CEBALLOS MARTÍN, Mª. M. Hacia la configuración del Estatuto del Municipio Turístico estudio del proyecto de Derecho de Municipio Turístico de Andalucía, Congreso de la Asociación Española de Expertos Científicos en Turismo, Ceuta, 2002; SUAY RINCÓN, J. y RODRÍGUEZ GONZÁLEZ, M., Las competencias turísticas de los municipios. En particular la categoría de los municipios turísticos. En Actas del I Congreso Universitario de Turismo, celebrado los días 27 a 29 de Octubre de 1998 en Peñíscola, Castellón, Valencia: Editorial Tirant lo Blanch.

17 BIDART CAMPOS, G. Manual de la Constitución reformada, III Tomos. Buenos Aires: Ediar Sociedad Anónima, Editora, Comercial, Industrial y Financiera, 2005; GELLI, M. A. Constitución de la Nación Argentina comentada y concordada. Buenos Aires: La Ley, 2006; HERNÁNDEZ, A. (H.). La descentralización del poder en el Estado argentino En Memoria del VII Congreso Iberoamericano de Derecho Constitucional. México: Instituto de Investigaciones Jurídicas, Universidad Nacional Autónoma de México, 2002, pp. 211 a 274; QUIROGA LAVIÉ, H., BENEDETTI, M. A. Y CENICASELAYA, M. Derecho Constitucional Argentino, $2 d a$. 
municipal $^{19}$, que si bien refieren a aspectos de carácter general relativos a la atribución de potestades entre la nación, las provincias y los municipios, permiten extraer de ellas los principios básicos de aplicación a la materia turística.

Por otra parte se han abordado puntualmente aspectos relativos a la distribución de competencias en turismo en diferentes obras jurídicas especializadas, abarcando temas diversos como: la concurrencia en materia de fomento turístico entre las provincias y el Estado federal ${ }^{20}$; el reparto de competencias turísticas entre la nación y las provincias ${ }^{21} \mathrm{o}$ las atribuciones propias del Estado federal y sus implicancias en la normativa turística nacional ${ }^{22}$.

En la Constitución Nacional, donde se establecen las pautas generales de distribución de competencias en la República Argentina, no existe mención taxativa a la actividad turística, como si ocurre en los textos constituciones de otros estados. A pesar de la falta de previsión específica en la materia, puede afirmarse que el fundamento para el reparto de competencias en la actividad turística, con carácter general, y de la regulación de los diferentes subsectores que la conforman, en especial, se encuentra en ella. Es así que es factible apreciar diferentes artículos de la Constitución Nacional que contienen preceptos que distribuyen competencias de manera directa en turismo y otros que, aunque no se relacionen con la actividad de forma directa, otorgan potestades que impactan sobre ésta.

En primer lugar puede sostenerse que entre la nación y las provincias el fundamento de distribución de competencias se encuentra en el juego armónico entre sus artículos 75 inc. 13 y 121 de la Constitución Nacional.

Edición. Santa Fé: Rubinzal-Culzoni. 2009; SAGÜES, Manual de derecho Constitucional, 2da. Edición. Buenos Aires: Editorial Astrea, 2012; SPOTA, A. Distribución de competencias en el Estado federal, ente éste y las provincias. El tema y sus nuevos aspectos frente a los procesos de integración y reajustes constitucionales", En Revista Jurídica La Ley 1992-D. Buenos Aires: La Ley, 1992, pp. 890-906; ZIULU, G. Derecho Constitucional. Buenos Aires, Buenos Aires: Ediciones Depalma, 1996; entre otros constitucionalistas argentinos.

18 ÁBALOS, M.G. (Coord.) Derecho público provincial y municipal. Buenos Aires: La Ley, 2004; ALBERDI, J. B. Obras completas, T. V, Elementos del Derecho Público Provincial Argentino. Buenos Aires: Imp., Lit. y Enc. de La Tribuna Nacional, 1886; HERNÁNDEZ, A. M. (Coord.) Derecho Público Provincial. Buenos Aires: Lexis Nexis, 2008; LUNA, H. D. Lecciones de derecho público provincial y municipal. La Plata: Ediciones Haber, 2014; SPOTA, A. Aproximación a la autonomía provincial a través de la jurisprudencia de la Corte Suprema de Justicia de la Nación”, En Anales de la Academia Nacional de Ciencias Morales y Políticas, Tomo XXXV, 2008; ZAVALÍA, C. Lecciones de Derecho Público Provincial, $2^{a}$ edición, Buenos Aires: Talleres Gráficos Argentinos L. J. Rosso, 1937; ZUCCHERINO, R. M. Derecho público provincial y municipal, II Tomos. La Plata: Editorial Lex, 1976; entre otros especialistas en derecho público provincial.

${ }^{19}$ ÁBALOS, M.G. Evolución y estado actual de la problemática municipal argentina: Interpretación jurisprudencial y recepción en el constitucionalismo provincial, En: CARNOTA, W.F. (Director) Derecho Federal. Sus implicancias prácticas. Buenos Aires: Grun Editora, 2005; HERNÁNDEZ, A. (H.) Derecho municipal. Parte General. México: Universidad Nacional Autónoma de México, 2003; ROSATTI, H. Tratado de derecho municipal, II Tomos. Buenos Aires: Rubinzal - Culzioni Editores, 2006, entre otros expertos en derecho municipal.

${ }^{20}$ CHÁVEZ, J. Turismo y cláusula de prosperidad, En KEMELMAJER DE CARLUCCI, A. Y BENÍTEZ, D. (coords.), Turismo, Derecho y Economía Regional. Santa Fé: Rubinzal Culzoni Editores, 2003, pp. 275-292.

${ }^{21}$ DEL BUSTO, E. El rol del derecho en el desarrollo del turismo, En WALLINGRE, N. Y VILLAR, A. (Comps) Gestión de municipios turísticos, instrumentos básicos de acción, Cap. III. Bernal: Editorial Universidad Nacional de Quilmes, 2014, pp. 57-90.

${ }^{22}$ GÜIDI, G. Características y alcances de la actividad turística y su regulación. Las leyes nacionales sobre turismo en el Digesto Jurídico Argentino, En BRENA, R. G. (Ed.) Digesto Jurídico Argentino, $1^{\text {a }}$ Edición, Buenos Aires, Buenos Aires: La Ley, 2014, pp. 803- 870. 
El primero de los artículos señala: Corresponde al Congreso: (...) 13. Reglar el comercio con las naciones extranjeras, y de las provincias entre sí. En esta norma se basa la competencia de la nación para la regulación del comercio ínter jurisdiccional y le otorga la facultad de reglamentar aquellas actividades comerciales, entre las que se puede ubicar a las turísticas, que se lleven a cabo entre más de una jurisdicción provincial, o entre éstas y un territorio sometido a jurisdicción federal o entre aquellas y la Ciudad Autónoma de Buenos Aires. En el enunciado artículo se ha justificado la competencia nacional para regular la actividad de intermediación en la prestación de servicios turísticos, a través de diferentes normas de aplicación en todo el país. Es, asimismo, el fundamento por el que compete a la nación la regulación del transporte turístico interprovincial y desde las provincias a cualquier territorio sometido a jurisdicción federal o a la Ciudad Autónoma de Buenos Aires.

El artículo 121, en tanto, establece: Las provincias conservan todo el poder no delegado por esta Constitución al Gobierno federal, y el que expresamente se hayan reservado por pactos especiales al tiempo de su incorporación. De conformidad con este precepto las provincias conservan todas las competencias en materia turística que no hayan expresamente delegado en la nación. En este caso cuentan con una facultad amplia para el dictado de normas en su territorio, en la medida que respeten los derechos constitucionalmente consagrados, de acuerdo a lo establecido en el artículo 28 de la Constitución Nacional y no invadan competencias que hayan delegado expresamente en la nación, de conformidad con lo determinado en su artículo 126. Basados en la disposición del artículo 121, llamada también "cláusula de reserva" las provincias han dictado leyes y reglamentaciones, de aplicación en sus ámbitos territoriales, y que tienen por objeto la regulación de las empresas, actividades y profesiones turísticas que allí se desarrollen. Entre ellas podemos enunciar: leyes provinciales de turismo, de alojamiento turístico, de turismo rural, de turismo de aventura, de turismo termal, de turismo religioso, de profesionales en turismo, de guías, etc.

El Estado federal cuenta, asimismo, con otras potestades, entre ellas las legislativas de aplicación en territorios sometidos a su jurisdicción. Esta competencia emana del artículo 75 inciso 30 de la Constitución Nacional que señala: Corresponde al Congreso: (...) 30 . ... dictar la legislación necesaria para el cumplimiento de los fines específicos de los establecimientos de utilidad nacional en el territorio de la República. Esto nos permite entender que con fundamento en el artículo citado, la nación tiene competencia en materia turística para el dictado de normas aplicables a los establecimientos de utilidad nacional y entendiendo este concepto de manera amplia en espacios portuarios y aeroportuarios que se encuentran sujetos a la jurisdicción federal o en aquellos ubicados en territorios declarados como áreas naturales protegidas por el gobierno federal.

Asimismo resulta notorio que la nación posee, además, otras competencias que inciden de manera directa sobre la actividad. Por su trascendencia puede enunciarse en primer lugar a las que emanan del artículo 75 inciso 18 de la Constitución Nacional. A través de esta norma se faculta al Congreso de la Nación al dictado de leyes tendientes a asegurar el bienestar general de todo el pueblo de la nación mediante normas de protección, fomento y estímulo. Señala el mencionado artículo: Corresponde al Congreso: (...) 18. Proveer lo conducente a la prosperidad del país, al adelanto y bienestar de todas las provincias, y al progreso de la ilustración, dictando planes de instrucción general y universitaria, y promoviendo la industria, la inmigración, la construcción de ferrocarriles y canales navegables, la 
colonización de tierras de propiedad nacional, la introducción y establecimiento de nuevas industrias, la importación de capitales extranjeros y la exploración de los ríos interiores, por leyes protectoras de estos fines y por concesiones temporales de privilegios y recompensas de estímulo. Si bien el turismo no puede ser considerado como una industria, sino que es una actividad correspondiente al sector terciario, diferentes normas han equiparado a ambas a los fines del otorgamiento de beneficios. En este punto resulta menester señalar que el artículo 125 de la Constitución Nacional establece metas similares para los gobiernos provinciales, de modo tal que se trata de potestades concurrentes entre las provincias y la nación ${ }^{23}$. De ahí que las provincias hayan dictado a lo largo de los años diferentes normas destinadas al fomento de la actividad turística en su territorio, en general, y en particular respecto de la actividad hotelera.

Por otro lado se encuentra el artículo 27 de la Constitución Nacional, que atribuye también al gobierno federal la competencia para afianzar las relaciones de paz con las potencias extranjeras por medio de tratados. En empleo de esas facultades se aprobaron diversos convenios internacionales que impactan en la actividad turística como: los relativos al transporte aéreo internacional, transporte de pasajeros y sus equipajes por mar, el transporte terrestre internacional, sobre el contrato de viaje (actualmente denunciado por la República Argentina), sobre facilidades aduaneras. Asimismo se han aplicado estas competencias para la ratificación de convenios bilaterales de cooperación en materia turística y en materia de servicios aéreos concretados con diferentes naciones.

Sin embargo y pese al amplio cúmulo de competencias antes citadas, no se agotan en aquellas las potestades del gobierno federal, ya que existen otras, que de un modo no directo tienen una incidencia clave en la actividad turística, entre ellas pueden encontrarse las contenidas el artículo 75 de la Carta Magna, relativas a diferentes materias: aduanera, tributaria, reglamentación de la libre navegación de los ríos interiores y habilitación de los puertos, monetaria y cambiaria, inmigratoria. Merece especial atención la potestad de dictar la legislación de fondo por parte del Congreso de la Nación, particularmente los Códigos Civil y de Comercio, facultando a la regulación de los diferentes contratos turísticos.

La reforma constitucional de 1994 introduce nuevas atribuciones de competencias para la nación con clara incidencia en cuestiones turísticas. Entre ellas: la de dictar las normas que contengan los presupuestos mínimos de protección de los recursos naturales, de la preservación del patrimonio natural y cultural y de la diversidad biológica, correspondiendo a las provincias el dictado de las normas necesarias para complementarlas sin que aquellas alteren las jurisdicciones locales, de conformidad con el artículo 41 de la Constitución Nacional. Puede advertirse claramente la importancia que esta norma tiene por el solo hecho de reconocer la trascendencia del patrimonio natural y cultural en su condición de atractivos turísticos. El otro aspecto que se presenta como novedoso es la potestad de la nación de dictar normas de protección a consumidores y usuarios, contenida en el artículo 42 de la Constitución Nacional, resultando clara la implicancia de esta norma cuando es de aplicación al turista en su condición de consumidor de servicios turísticos.

Sólo a título enunciativo pueden, además, advertirse otras competencias de la nación

${ }^{23}$ CHÁVEZ, J. Turismo y cláusula de prosperidad, En KEMELMAJER DE CARLUCCI, A. Y BENÍTEZ, D. (coords.), Turismo, Derecho y Economía Regional. Santa Fé: Rubinzal Culzoni Editores, 2003, p. 281. 
como la promoción del turismo en el país y en el extranjero, la planificación general del turismo en el territorio de la nación, la elaboración de estadísticas turísticas, las referidas a la aprobación de los planes de estudio, condiciones de obtención, expedición, homologación de los títulos profesionales del turismo, etc.

En lo que respecta a las provincias la atribución de competencias en materia turística, a partir de los preceptos de la Constitución Nacional, es sumamente amplia tal como se ha enunciado precedentemente, y sólo se encuentra limitada por aquellas que han sido expresamente delegadas en el estado federal, a las que se ha hecho mención con anterioridad, o por aquellas que se encuentran prohibidas a éstas contenidas esencialmente, aunque no exclusivamente, en el artículo 126 de la Constitución Nacional.

Efectuado un análisis del constitucionalismo provincial, puede advertirse que la mayor parte de las provincias argentinas han hecho mención a la actividad turística en sus textos constitucionales, atribuyendo competencias para su regulación en los respectivos territorios, y en otros casos destacando el papel relevante del turismo como actividad económica y social. Asimismo han determinado en pocos casos competencias turísticas para los municipios. Si bien son múltiples las menciones y diferentes los tratamientos que se otorga a la actividad turística en las normas constitucionales provinciales, no en todos los casos tal mención constituye un factor de atribución de competencias, no obstante se aprecia como valiosa su inclusión en los textos constitucionales, ya que permite advertir la importancia que ha cobrado el turismo en las diferentes provincias.

Al hacer referencia a las competencias que las provincias pueden asumir, en uso de la reserva de facultades en materia de turismo, se ha mencionado a la potestad de ordenamiento de la actividad en su territorio, a través de las llamadas leyes provinciales de turismo. Esta herramienta jurídica ha sido empleada por las provincias como un instrumento por medio del cual se desarrollan las competencias turísticas en su territorio, a la vez que ha servido para fijar la distribución de competencias en la materia entre éstas y los municipios. Las enunciadas normas, pese a las particularidades que las diferencian, poseen rasgos y valores en común, entre los que destacan el reconocimiento a la actividad turística como de interés prioritario; determinación de objetivos: la promoción, preservación de recursos, mejora de los habitantes, calidad, participación; designación de una autoridad de aplicación y establecimiento de sus funciones; definición de las áreas consideradas de carácter turístico; creación de organismos de turismo; determinación de los prestadores y sus obligaciones, creación de Consejos Asesores; importancia del turismo social; fijación como principio esencial a la protección del turista; creación de fondos de promoción y establecimiento de sanciones ante los incumplimientos ${ }^{24}$. Por su gran trascendencia en el desarrollo del turismo local, una mención especial merece la atribución de potestades que algunas leyes provinciales de turismo efectúan respecto de la declaración de Departamentos, Municipios o Comunas Turísticas. Puede afirmarse que las Leyes Provinciales de Turismo se han convertido en el instrumento más eficaz de atribución de competencias en materia de turismo, estableciendo una distribución entre las provincias y los municipios. Es precisamente en ellas en las que ha de analizarse, en primer lugar, cuales son las potestades con que cuentan cada uno de estos entes para intervenir en la actividad turística local.

${ }^{24}$ DEL BUSTO, E. Política y legislación turística y hotelera. Bernal: Universidad Nacional de Quilmes, 2007, p. 215. 
Además de las competencias turísticas de carácter general de las provincias es importante enunciar aquellas que recogen las diferentes normas sectoriales (alojamiento, turismo rural, turismo activo o de aventura, turismo termal, profesionales en turismo, guías, etc.) que cada provincia dicta. Estas normas son de naturaleza distinta y tienden a establecer en el ámbito territorial específico una regulación particularizada de algunas actividades turísticas, que por su trascendencia merecen una específica intervención del Estado en ejercicio de su poder de policía.

Se ha puesto de resalto que las últimas décadas, caracterizadas por la marcada globalización, han dado lugar a una nueva territorialidad de responsabilidades, que ha redefinido los roles y asignaciones del Estado-nación y ha dado lugar al fortalecimiento de los gobiernos de escalas locales ${ }^{25}$. La República Argentina no ha sido ajena a ese fenómeno como lo muestra la reforma constitucional de 1994 que concluye un proceso de descentralización de funciones desde la nación hacia las provincias y de éstas hacia los municipios, que cobran una importancia mayor en el desarrollo local.

El artículo 5 de la Constitución Nacional impone a las provincias, desde los orígenes del Estado argentino, la obligación de asegurar el régimen municipal, pero no es sino hasta la reforma antes enunciada que se establece el deber de garantizar su autonomía. Este deber se encuentra receptado en el artículo 123, que señala: Cada provincia dicta su propia constitución, conforme a lo dispuesto por el art. $5^{\circ}$ asegurando la autonomía municipal y reglando su alcance y contenido en el orden institucional, político, administrativo, económico $y$ financiero. Pese a la naturaleza constitucional de las fuentes, resulta menester acudir a otras normas a fin de poder conocer cuáles son las competencias atribuidas a los municipios en materia turística en nuestro país.

En primer lugar encontramos a los textos constitucionales provinciales que hacen referencia a las competencias de los municipios en materia turística, y que en general establecen que es deber y atribución de sus gobiernos el fomento de la actividad, en otros la promoción del turismo social, y en muchos casos se lo emparenta con actividades como el deporte y la recreación.

Las Leyes Provinciales de turismo, otorgan algunas atribuciones a los municipios, departamentos o comunas: Las mismas son de disímil entidad, entre las más comunes se pueden mencionar: participar en el desarrollo de productos turísticos; en la coordinación de planes, programas y proyectos de desarrollo turístico; participar en la diagramación y articulación de zonas, corredores, circuitos o regiones turísticas; brindar información a prestadores y turistas; integrar el Consejo o Comisión Provincial de Turismo; participar en la protección y conservación del patrimonio cultural, histórico, paisajístico, natural, costumbrista, ambiental y ecológico; participar de programas tendientes a fomentar y desarrollar el turismo social, la recreación y el ocio; solicitar la declaración como Departamento o Municipio Turístico; propiciar el otorgamiento de beneficios impositivos, tributarios y crediticios. Y en menor medida: intervenir en la inscripción, supervisión y fiscalización de los servicios turísticos; participar en la distribución de los recursos que integran el Fondo Provincial de Turismo; orientar y proteger a los turistas en la defensa de sus

25 WALLINGRE, N. Definición y parámetros de identificación de municipios turísticos En WALLingRE, N. Y VILLAR, A. (comps.) Gestión de municipios turísticos, instrumentos básicos de acción, Cap. I, Bernal, Editorial Universidad Nacional de Quilmes, 2014, pp. 17-40. 
derechos; participar en la definición y coordinación de las políticas en materia de información, señalización, planificación y ordenamiento territorial.

En las Leyes Provinciales de Turismo que contienen la figura del Departamento, Municipio o la Comuna Turística, se lo define y caracteriza, se plantean acciones conjuntas entre éstos y las provincias como la ejecución de planes, programas y proyectos desarrollo turístico provincial, la supervisión y fiscalización de los servicios turísticos que se prestaren en cada jurisdicción, el fomento e integración de la actividad turística en sus planes de desarrollo local. Se identifican en dichas normas, asimismo, algunas atribuciones específicas tales como la creación de centros de información turística, la formulación de proyectos turísticos, la participación en el desarrollo de planes de ordenación del territorio conforme con el espacio turístico existente, la elaboración de estadísticas, la actualización del inventario de atractivos turísticos, la coordinación con la autoridad competente de la seguridad personal y la de los bienes de los turistas, el incentivo y promoción de las actividades dirigidas al desarrollo del turismo y la recreación de las comunidades, la coordinación de un plan de señalización local, el velar por el ornato y mantenimiento de plazas, parques, paseos y demás sitios turísticos e históricos de la ciudad, la organización y promoción de ferias y festividades turísticas, la gestión de los servicios turísticos que tuvieran a su cargo.

Las atribuciones antes mencionadas se ejercitan sin perjuicio de aquellas competencias propias de los entes municipales de turismo que surgen de los instrumentos jurídicos de su creación y que en términos generales se caracterizan por ser: promover sus recursos turísticos, obtener y brindar información turística, promover el destino, fomentar las inversiones, brindar capacitación y asistencia técnica, efectuar investigaciones y ejecutar las planificaciones elaboradas, promover la realización de actividades recreacionales para la población local, fiscalizar el cumplimiento de las normas aplicables a los prestadores de servicios turísticos, en los casos en los que cuentan con funciones delegadas o competencias propias y propiciar la resolución de los conflictos que se susciten con los turistas.

Además de las competencias específicas en materia turística los municipios cuentan con otras que habilitan el dictado de normas que impactan sobre aquella. Éstas surgen tanto de las Leyes Orgánicas Municipales que cada provincia sanciona, como de las Cartas Orgánicas Municipales, en el caso de los municipios que se encuentran habilitados a su dictado. Entre las cuestiones sobre las que dicha normativa puede operar encontramos: la planificación urbana y la determinación de normativa de edificación, la gestión de residuos, imposición de tributos diversos, el transporte en en su territorio y sus limitaciones, la determinación de pautas para la publicidad comercial en espacios públicos, las restricciones al uso de espacios costeros y el ordenamiento de instalaciones en éstos, la imposición de exigencias de insonorización en salas y espectáculos al aire libre, el aprovechamiento de recursos termales, el control del transporte urbano, la preservación del patrimonio cultural, histórico, paisajístico, natural, costumbrista, ambiental y ecológico, la prevención contra incendios, habilitaciones comerciales e industriales, controles sanitarios y bromatológicos, etcétera.

\section{ATRIBUCIÓN DE COMPETENCIAS TURÍSTICAS EN MUNICIPIOS DE RECIENTE DESARROLLO}

Para el análisis de la atribución de competencias turísticas en municipios argentinos se eligieron destinos de reciente desarrollo ubicados en diferentes regiones del país, que: se 
hubieran constituido como tales a partir de 1990, en los que el turismo fuera un sector de desarrollo (principal, o un dinamizador y diversificador de su economía y desarrollo social), que se encontraran, al menos, en la etapa introductoria de la evolución del ciclo de vida del turismo y que se tratara de pequeños o medianos municipios.

Los entes locales respecto de los que se efectuó el estudio son: la comuna de Cayastá, situada en la provincia de Santa Fe, que tiene a la pesca y la agricultura como actividad primaria y atractivos turísticos como un parque arqueológico declarado Monumento Histórico Nacional, el río San Javier, el Museo del recuerdo (almacén de ramos generales) y la Iglesia Natividad de la Virgen. El municipio de Chajarí, ubicado en la provincia de Entre Ríos, con producción citrícola y actividad forestal y ganadera y en menor medida la horticultura y apicultura y cuyo principal atractivo turístico es el Complejo Parque Termal, al que se suman la pesca deportiva y las playas en el Lago Salto Grande. El municipio de Federación, localizado en la provincia de Entre Ríos, cuya actividad económica se estructura sobre la base de la producción citrícola, la apicultura, la forestación, los aserraderos y su principal atractivo turístico es el Parque Termal y las playas sobre el río Uruguay, a los que se suma la pesca deportiva, la reserva forestal de Chaviyú y actividades de turismo de aventura. El municipio de Malargüe, situado en la provincia de Mendoza, cuyas principales actividades económicas históricamente fueron las extractivas: minera y petróleo y sus atractivos turísticos son el centro internacional de esquí en el Valle de Las Leñas, el parque volcánico provincial La Payunia, así como la práctica de actividades de turismo de aventura. El municipio de Paso de la Patria, ubicado en la provincia de Corrientes, cuyo principal atractivo turístico se encuentra en sus balnearios así como en la pesca deportiva, complementado por actividades de turismo rural y alternativo. El municipio de San José, localizado en la provincia de Entre Ríos, cuya actividad económica gira alrededor de la producción avícola, apícola y hortícola y el principal atractivo turístico es su Complejo termal, a la vez que cuenta con una reserva natural y un balneario en el que se pueden practicar deportes náuticos y de aventura, además de la pesca deportiva. El municipio de San Nicolás, situado en la provincia de Buenos Aires, cuya actividad económica principal es la industria siderúrgica, complementada por la actividad agropecuaria y un importante puerto comercial y entre sus atractivos turísticos se pueden mencionar el Santuario de la Virgen del Rosario -uno de los principales centros de peregrinación marianos de la Argentina, el paseo costero del río Paraná, el Museo Casa del Acuerdo, donde se suscribió el Acuerdo de San Nicolás, base de la organización del Estado argentino. El municipio de Villa Elisa, ubicado en la provincia de Entre Ríos, cuya producción principal es la avícola y la ganadería extensiva, acompañada por el sector arrocero y la actividad forestal y entre sus atractivos turísticos posee un Complejo Termal, la Estancia Museo El Porvenir, el Tren Histórico del Ferroclub Central Entrerriano, a los que pueden sumarse actividades de turismo rural. El municipio de Villa Pehuenia, localizado en la provincia de Neuquén, cuya principal actividad económica es la ganadería ovina, bovina y la explotación forestal; y sus principales atractivos turísticos son el centro de esquí Batea Mahuida, el lago Quillén, circuitos entre araucarias y pehuenes milenarios, a la vez que pueden practicarse diversos deportes de aventura en su entorno, así como la pesca deportiva. El municipio de Villa Unión, situado en la provincia de La Rioja, en el que se desarrollan tanto actividades agropecuarias como vinculadas con la producción vitivinícola y olivícola y cuenta con actividad ganadera ovina y caprina y el atractivo turístico más importante de la localidad es el Parque Nacional Talampaya, declarado por la Unesco Patrimonio Natural de la Humanidad en el año 2000, y complementan la oferta turística del destino el Cañón del 
Triásico, que se encuentra ubicado en la Reserva Municipal "Banda Florida" y el Vallecito Encantado.

En primer lugar se analizaron las disposiciones de las Constituciones provinciales, en las que se ubican los entes locales antes mencionados para verificar si de ellas surgen competencias de los municipios en materia turística. En este primer estadio puede afirmarse que en general los textos constitucionales no cuentan con un sistema expreso de reparto de competencias en la materia en trato.

La Constitución de la provincia de Entre Ríos impone el mandato al Estado de promover la actividad turística, favorecer la iniciativa e inversión pública y privada, fomentar y sostener el turismo social, coordinando con las representaciones sectoriales, municipios y comunas, una política sostenible y sustentable, para el desarrollo armónico de la actividad (artículo 69). Determina por otra parte que el turismo es una de las competencias de los municipios (artículo 240 inc. 21 k). Asimismo, el análisis del artículo 240, que señala las competencias de los municipios, permite extraer otras que tienen incidencia en la materia, entre ellas las de: gobernar y administrar los intereses locales (inciso 1); la de establecer, recaudar y administrar sus recursos, rentas y bienes propios orientados al bien común (inciso 11); regular, disponer y administrar, en su ámbito de aplicación, los bienes del dominio publico y privado municipal; ejercer el poder de policía y funciones respecto a: el planeamiento y desarrollo social (inciso 21 apartado a), Seguridad, higiene, bromatología, pesas y medidas (inciso 21 apartado c), planeamiento y ordenamiento territorial, vialidad, rutas y caminos, apertura, construcción y mantenimiento de calles (inciso 21 apartado d), planes edilicios, control de la construcción, (...) diseño y estética urbana, plazas, paseos, edificios públicos y uso de espacios públicos (inciso 21 apartado e), transito y transporte urbanos (inciso 21 apartado f), protección del ambiente, del equilibrio ecológico y la estética paisajística (inciso 21 apartado g), defensa de los derechos de usuarios y consumidores (inciso 21 apartado j); fomentar instituciones culturales y expresiones artísticas y artesanales (inciso 22); preservar y defender el patrimonio histórico, cultural, artístico y arquitectónico (inciso 23); concertar con la Nación, las provincias y otros municipios y comunas, convenios interjurisdiccional, pudiendo crear entes o consorcios con conocimiento de la Legislatura (inciso 24).

La Constitución de la provincia de Corrientes señala que entre las bases para la formulación de políticas de Estado, se debe promover el impulso del turismo (Disposición Transitoria Primera inc. 4 k). Asimismo se incorpora al turismo cuando se hace referencia a la conformación del Consejo de Crecimiento Económico y Desarrollo Social (Disposición Transitoria Primera inc. 8). Entre las competencias municipales con incidencia en turismo pueden mencionarse: la participación en los organismos de control y en la confección o modificación del régimen regulatorio de los servicios públicos de competencia provincial (artículo 48); la gestión integral de los residuos y su utilización productiva (artículo 55); el ordenamiento del uso del suelo y la regulación del desarrollo urbano, suburbano y rural (artículo 62). Entre las atribuciones y deberes específicos del municipio con incidencia en turismo, enunciadas en el artículo 225 inciso 6, que faculta al dictado de ordenanzas y reglamentaciones se encuentran: habilitación de comercios y actividades económicas (apartado a), higiene, moralidad y salubridad pública (apartado b), servicios públicos, y de interés general (apartado c), bromatología y control de alimentos (apartado d), urbanismo (apartado e), recolección y disposición final de residuos (apartado f), obras públicas y viales, 
construcciones urbanas, parques y paseos públicos (apartado h), vialidad, tránsito y transporte apartado i), uso de calles, veredas, superficie, subsuelo y espacio aéreo (apartado j), seguridad ciudadana (apartado o), defensa de los derechos de usuarios y consumidores (apartado p), protección, preservación y promoción del medio ambiente, del paisaje, del equilibrio ecológico y control de la polución ambiental (apartado r), entre otras.

La provincia de Neuquén en su Constitución faculta al Poder Legislativo al dictado de leyes sobre turismo (artículo 101 inc. 29). Algunas de las competencias municipales con incidencia en turismo son: el dictado de normas ambientales (artículo 92); cobro de los impuestos provinciales para los que se los faculte (artículo 151). Asimismo cuentan con potestades para la recaudación tasas por servicios, impuestos, derechos, patentes, licencias, contribuciones por mejoras, multas y recargos por contravenciones (artículo 229). Son atribuciones comunes a todos los municipios, de acuerdo con el artículo 273: las referentes a su plan edilicio, apertura, construcción y mantenimiento de calles, plazas, parques y paseos; tránsito y vialidad; transportes y comunicaciones urbanas, edificación y construcciones, servicios públicos locales, higiene, salud pública y, en general, todas las de fomento o interés local (inciso 1); creación y recaudación de impuestos, tasas o cotizaciones de mejora (inciso $b$ y c); contratar servicios públicos y otorgar concesiones a particulares (inciso f); dictar normas edilicias tendientes a la seguridad y estética de las construcciones (inciso i); acordar las licencias comerciales (inciso j); celebrar acuerdos con la Provincia, el Gobierno Federal u organismos descentralizados para el ejercicio coordinado de facultades concurrentes e intereses comunes (inciso $\mathrm{m}$ ); celebrar convenios entre sí y constituir organismos intermunicipales (inciso $\mathrm{n}$ ).

En el caso de las restantes provincias no existe mención expresa al turismo, no obstante pueden extraerse competencias de los municipios con incidencia en él, que emanan de dichas constituciones.

La Constitución de la Provincia de Buenos Aires determina en su artículo 192 las atribuciones inherentes al régimen municipal. Entre las que tienen incidencia en turismo encontramos: el ornato y salubridad y la vialidad pública (inciso 4); el dictado de ordenanzas y reglamentos (inciso 6). Asimismo se encuentran facultados para la creación de impuestos o contribución de mejoras (artículo 193).

En el caso de la Constitución de la Provincia de La Rioja el artículo 157 determina que las Cartas Orgánicas Municipales establecerán las estructuras funcionales del municipio, conforme a los requerimientos del Departamento, incorporando los aspectos de educación, salud pública, gobierno y cultura, hacienda, obras y servicios públicos, y el desarrollo social y económico. Ellas deben asegurar, en los aspectos vinculados al turismo: la defensa del medio ambiente (inciso 7) y la protección y defensa de los consumidores y usuarios (artículo 9).

La Constitución de la Provincia de Mendoza delega al dictado de una Ley Orgánica de las Municipalidades, el deslinde de las atribuciones y responsabilidades de cada departamento, confiriéndole las facultades necesarias para que ellos puedan atender eficazmente a todos los intereses y servicios locales (artículo 199). De acuerdo con el artículo 200, son atribuciones inherentes a las municipalidades, que inciden en turismo: el dictado de las ordenanzas y reglamentos, dentro de las atribuciones conferidas por la Constitución y por la Ley Orgánica de Municipalidades (inciso 6) y en particular el ornato y salubridad (inciso 
$3)$.

La Constitución de la Provincia de Santa Fe, por último, delega la organización el régimen municipal y comunal, a la Legislatura Provincial (artículo 55 inciso 5). Con carácter general cuentan con las atribuciones necesarias para una eficaz gestión de los intereses locales (artículo 107 inciso 3 párrafo primero). Entre sus atribuciones se establecen: crear, recaudar y disponer libremente de recursos propios provenientes de las tasas y demás contribuciones que establezcan en su jurisdicción. (Artículo 107 inciso 3 párrafo segundo).

El análisis de las Leyes Orgánicas de Municipios, sancionadas por las legislaturas provinciales, permite afirmar que en la mayoría de los casos no se han otorgado, a través de este instrumento, competencias en materia de turismo a aquellos, aunque si otras que tienen incidencia en la actividad.

La Ley Orgánica de las municipalidades de la Provincia de Buenos Aires (Decreto Ley 6769/58), en su artículo 27, establece que corresponde al Consejo Deliberante reglamentar entre otros aspectos: la radicación, habilitación y funcionamiento de los establecimientos comerciales; la conservación de monumentos, paisajes y valores locales de interés tradicional, turístico e histórico; las condiciones de higiene y salubridad de espacios públicos; la elaboración, transporte, expendio y consumo de materias o artículos alimentarios; la sanidad vegetal; la prevención y eliminación de las molestias de origen sonoro y lumínico, la contaminación ambiental y de los cursos de agua y el aseguramiento de la conservación de los recursos naturales; los servicios públicos de transporte de pasajeros; los servicios de vehículos de alquiler y sus tarifas, entre otras. El artículo 29 faculta a la creación de impuestos o contribuciones de mejoras.

La Ley Orgánica de las Municipalidades de la Provincia de Corrientes (Ley 6042), en su artículo 70, al referirse a los deberes y facultades del Concejo Deliberante, detalla: reglamentar la construcción de edificios públicos y privados; 14. Dictar las reglamentaciones necesarias para asegurar los derechos de usuarios y consumidores; reglamentar la habilitación de comercios; dictar las normas bromatológicas; disponer la recolección y disposición de residuos; dictar disposiciones relativas a la limpieza y alumbrado público; dictar las medidas para la preservación del ambiente; elaborar planes estratégicos de desarrollo y planeamiento territorial; dictar normas de higiene y seguridad ciudadana; reglamentar la conservación de calles, caminos, plazas, parques y paseos públicos; preservar el patrimonio cultural y arquitectónico; fijar las condiciones de uso del suelo urbano, su zonificación, y condiciones urbanísticas en general; fijar las cuotas de los impuestos, tasas y contribuciones, entre otras.

La Ley de Régimen Municipal de la provincia de Entre Ríos (Ley 10027) determina en su artículo 11 las competencias de los Municipios, entre ellas: reglamentación y fiscalización de las construcciones; otorgamiento de concesiones de servicios públicos; reglamentación de la publicidad; el ejercicio de la policía higiénica y sanitaria; la conservación y uso de plazas, paseos y parques; fijar los impuestos, las tasas y contribuciones municipales; reglamentar el ordenamiento urbanístico, entre otras. Asimismo en su artículo 95, al referirse a los deberes y facultades del Concejo Deliberante, establece: dictar normas tendientes a preservar el patrimonio histórico, el sistema ecológico, los recursos naturales y el medio ambiente.

La Ley Orgánica de las Municipalidades de la provincia La Rioja (Ley 6843) en su 
artículo 28 hace una mención específica a las potestades turísticas de los municipios, al señalar: El Municipio promueve toda actividad turística, reglamentando y fiscalizando los servicios necesarios para tal fin, en concordancia con la normativa y atribuciones en la materia del Estado Provincial. Podrá destinar parte de su presupuesto municipal para la construcción de infraestructura y difusión turística en el territorio nacional y/o en el extranjero, como así también podrá fomentar las inversiones de capitales privados o públicos tendientes a su desarrollo en la Región. Asimismo, en el Capítulo II determina otras atribuciones y competencias: preservación del patrimonio cultural, histórico, arquitectónico y arqueológico; reglamentar las habilitaciones comerciales y las normas de higiene, salubridad y seguridad; definir la política urbanística del Municipio, entre otras. Al referirse a las atribuciones y deberes del Concejo Deliberante, en su artículo 74 adiciona: fijar la política tributaria del Municipio; determinar la altura de los edificios particulares, las líneas de edificación y de ochavas; dictar Ordenanzas de protección de animales y vegetales autóctonos y autorizar, prohibir o reglamentar la caza y la pesca; reglamentar el uso y ocupación del espacio aéreo, subsuelo de calles y aceras, ordenar el tránsito y de transporte urbano de pasajeros; auspiciar y estimular las festividades cívicas y religiosas, patrióticas y populares.

La Ley Orgánica de Municipalidades de la Provincia de Mendoza (Ley 1079) en sus artículos 71 a 89, al referirse a las atribuciones y deberes del Concejo Deliberante, establece: dictar ordenanzas sobre higiene, moralidad, ornato, vialidad vecinal, administración comunal, bienestar económico de sus habitantes y demás objetos propios de su institución, sobre contribuciones y servicios; dictar el reglamento general de edificación; reglamentar los servicios de aguas corrientes, sanitarios, electricidad, gas, teléfono; proveer la construcción, conservación y mejoras de los edificios y monumentos públicos, paseos, plazas; organizar la policía e inspección municipal.

La Ley Orgánica de las Municipalidades de la Provincia de Neuquén (Ley 53) en sus artículos 101 a 119, determina las competencias del Concejo Deliberante: la instalación de los establecimientos comerciales; el transporte en general; la construcción de los edificios particulares y públicos; la protección de los animales, árboles, jardines y paseos públicos; el mejoramiento de calles, caminos, plazas, paseos públicos; sancionar las ordenanzas impositivas; disponer la prestación de los servicios públicos, entre otros.

La Ley Orgánica de las Municipalidades de la Provincia de Santa Fe (Ley 2756), en su artículo 39, inciso 65 hace una mención especial respecto de las potestades turísticas de los municipios, al señalar que compete al Consejo Municipal: Organizar la dirección autárquica municipal de parques, balnearios, paseos populares y turismo...Asimismo, entre otras atribuciones recogidas en el artículo citado se encuentran: dictar ordenanzas sobre higiene, moralidad, ornato, vialidad y sobre los demás objetos propios a la institución municipal; crear impuestos y rentas municipales; reglamentar la construcción de edificios particulares; dictar ordenanzas relativas a la seguridad ciudadana; reglar la vigilancia en el expendio de las sustancias alimenticias, entre otros.

Resulta importante establecer que el único municipio estudiado que cuenta con Carta Orgánica Municipal -en el que es sólo es aplicable la Ley Orgánica de las Municipalidades provincial en materias no regladas o con carácter supletorio e interpretativo-, es el de Paso de la Patria, provincia de Corrientes. En dicha norma, al enumerar las atribuciones y deberes del Concejo Deliberante, se incluye: la reglamentación de las actividades turísticas, deportivas y 
recreativas (...) (artículo 76 inciso 10).

Indagando en las Leyes Provinciales de turismo, de aplicación en las localidades objeto del presente estudio se advierte que éstas otorgan algunas atribuciones a los municipios, departamentos o comunas, entre ellas: participar en el desarrollo de productos turísticos, en la coordinación de planes, programas y proyectos de desarrollo turístico, en la inscripción, supervisión y fiscalización de los servicios turísticos, diagramación y articulación de zonas o regiones turísticas, requerir y brindar información a prestadores y turistas, orientar y proteger a los turistas en la defensa de sus derechos, proponer la declaración de emergencia o desastre turístico (Ley 14209 de la provincia de Buenos Aires); la coordinación con los organismos provinciales: en todas aquellas cuestiones vinculadas directa o indirectamente al desarrollo turístico, el desarrollo de productos turísticos, el ordenamiento territorial en regiones, zonas, corredores, circuitos, rutas y áreas de recreación y/o esparcimiento, en la protección del patrimonio cultural, histórico, costumbrista, paisajístico y natural, participar por vía de delegación en los trámites de inscripción en el Registro Provincial de Prestadores de Servicios Turísticos, su inspección y fiscalización, la orientación y protección de los turistas en la defensa de sus derechos, participar en el Plan estratégico de Turismo, proponer a la Autoridad de Aplicación provincial la declaración de Emergencia o Desastre Turístico (Ley 6309 de la provincia de Corrientes); participar en la propuesta del ordenamiento territorial en microrregiones, regiones, zonas, corredores, circuitos, rutas y áreas de recreación y/o esparcimiento y en la protección y conservación del patrimonio cultural, histórico, paisajístico, natural, costumbrista, ambiental y ecológico, participar de acciones coordinadas destinadas a la promoción de la oferta turística, integrar la Comisión Provincial de Turismo, incentivar el desarrollo turístico de bajo impacto sobre el ambiente, participar de programas tendientes a fomentar y desarrollar el turismo social, la recreación y el ocio (Ley 9946 de la provincia de Entre Ríos); participar en la protección y conservación del patrimonio cultural, histórico, paisajístico, natural costumbrista, ambiental y ecológico, solicitar la declaración como Departamento Turístico, integrar el Consejo Provincial de Turismo, propiciar el otorgamiento de beneficios impositivos, tributarios y crediticios (Ley 8820 de la provincia de La Rioja); realizar en conjunto con el organismo provincial o en forma delegada, acciones o programas de promoción, fiscalización, fomento, publicidad o desarrollo de las actividades turísticas; y también operativos de control, en toda su amplitud, participar del Fondo de Promoción Turística de la Provincia y del Consejo Asesor de Municipalidades, (Ley 8845 de la provincia de Mendoza); participar en la propuesta del ordenamiento territorial en regiones, zonas, corredores, circuitos, rutas y áreas de recreación y/o esparcimiento, la coordinación para la protección del patrimonio natural y cultural, intervenir en acciones coordinadas destinadas a la jerarquización y promoción de la oferta turística, integrar el Consejo Provincial de Turismo (Ley 2414 de la provincia de Neuquén).

Ampliando el abordaje de las Leyes Provinciales de Turismo estudiadas, cabe referirse a aquellas que contienen la figura del Departamento, Municipio o la Comuna Turística, y sus particularidades. En el caso de la Ley 9946 de la provincia de Entre Ríos, se establece su conceptualización, impulsa su constitución, y determina algunas competencias como: el fomento e integración la actividad turística en sus planes de desarrollo local, la formulación de proyectos turísticos, desarrollar en forma armónica los planes de ordenación del territorio, conforme con el espacio turístico existente, elaborar y mantener actualizadas las estadísticas de la oferta y la demanda turística, elaborar y actualizar el inventario de atractivos turísticos, velar por la seguridad personal y la de los bienes de los turistas y/o visitantes, coordinar un 
plan de señalización local con énfasis en los sitios de interés turístico, histórico, cultural o natural, velar por el ornato y mantenimiento de plazas, parques, paseos y demás sitios turísticos e históricos, organizar y promover ferias y festividades turísticas, incentivar y promover las actividades dirigidas al desarrollo del turismo y la recreación de las comunidades. La Ley 8820 de la provincia de La Rioja, en tanto, define a los Departamentos Turísticos, dejando a cargo de la autoridad de aplicación de la norma su declaración, a solicitud de aquel. La Ley 2414 de la Provincia de Neuquén, en tanto, define la figura del Municipio Turístico y determina que la autoridad de aplicación de la norma debe coordinar con estos municipios acciones respecto de la ejecución de planes, programas y proyectos que coadyuven al desarrollo turístico provincial, en relación con la supervisión y fiscalización de los servicios turísticos que se prestaren en cada jurisdicción.

\section{CONCLUSIONES}

La distribución de competencias turísticas en la República Argentina otorga a la nación y las provincias la mayor parte de las potestades para regular la actividad, no obstante, se aprecia también, que los municipios, comunas o departamentos cuentan con atribuciones amplias en lo que respecta a materias que tienen una importante incidencia respecto del turismo en sus territorios.

Si bien las primeras normas que han dado marco jurídico al turismo se pueden ubicar en el ámbito del Estado nacional, en la presente época se aprecia una amplia participación de las provincias en la conformación de la normativa turística. Dada la indiscutible importancia que cabe a los municipios respecto de la actividad, ya que es precisamente el nivel local, el que presenta un incremento en la participación de las administraciones en el desarrollo y gestión del turismo ${ }^{26}$, es previsible una futura etapa donde la normativa que conforma el derecho del turismo, encuentre un mayor desarrollo en los entes municipales.

La descripción de las competencias de los municipios estudiados, en la mayoría de los casos, se encuentran precedidas por el termino "participar" lo que permite afirmar que las diferentes acciones son impulsadas por las provincias, que son quienes definen la política turística común, pero que a la vez impactan de manera sustantiva en las políticas turísticas locales. Es de esperarse en el futuro un mayor grado de protagonismo por parte de los municipios en la definición de estos aspectos.

Se ha podido apreciar, por otra parte, que el grado diverso de autonomía de los municipios estudiados, de primera, segunda o tercera categoría, no importa necesariamente un menoscabo a sus potenciales competencias en cuanto al turismo se refiere, excepción hecha respecto del municipio de que cuenta con Carta Orgánica, que se encuentra facultado a regular la actividad turística que se desarrolla en su territorio.

Otro aspecto que se ha verificado es que pese a desarrollarse las actividades de los prestadores turísticos en el territorio sometido a la jurisdicción de los municipios, éstos cuentan con escasas facultades para su regulación. Por sólo citar algunos ejemplos: la intermediación turística y el tiempo compartido se encuentran bajo la potestad normativa del

${ }^{26}$ ORGANIZACIÓN MUNDIAL DEL TURISMO. Guía para administraciones locales: desarrollo turístico sostenible. Madrid: Organización Mundial de Turismo, 1999, p. 9. 
Estado nacional y el alojamiento, el turismo rural, el turismo de aventura, la actividad de los guías y profesionales en turismo son competencias provinciales.

Asimismo se advierte que los municipios cuentan con competencias que inicialmente no son turísticas en un sentido estricto, pero que pueden ser empleadas para potenciar la actividad (entre ellas las urbanísticas, relativas a la accesibilidad, el ambiente, la seguridad, etcétera).

Por último, puede afirmarse que las Leyes Provinciales de Turismo que recogen la figura del "municipio o departamento turístico" y que determinan sus atribuciones y deberes aún son escasas. Asimismo, este reconocimiento, en los casos en los que se verifica, no es acompañado de otros instrumentos legales o económicos, como potestades tributarias específicas o incentivos de otra especie, que ayuden a solventar las mayores erogaciones que tal condición impone, por recolección de residuos, instalación de equipamiento para la accesibilidad, mejoras en servicios de asistencia primaria, saneamiento, protección del medio natural, seguridad, tráfico, vigilancia y limpieza de playas, agua, alcantarillado, alumbrado, etcétera.

A modo propositivo se plantea la necesidad de otorgar mayores atribuciones a los municipios, tendentes a acompañar la política turística en el nivel local y a potenciar un desarrollo sostenible en sus territorios. Esto así, en tiempos en que se habla de la necesidad de una mayor descentralización, y máxime teniendo en cuenta que son éstos quienes detentan la condición de destinos en los que se localizan los recursos turísticos, cuentan con potestades en materias que impactan de manera sustantiva en el turismo y se encuentran en una posición privilegiada debido a la proximidad en el contacto con los turistas.

\section{REFERENCIAS BIBLIOGRÁFICAS}

ÁBALOS, M.G. (Coord.) Derecho público provincial y municipal. Buenos Aires: La Ley, 2004.

ÁBALOS, M.G. Evolución y estado actual de la problemática municipal argentina: Interpretación jurisprudencial y recepción en el constitucionalismo provincial, En: CARNOTA, W.F. (Director) Derecho Federal. Sus implicancias prácticas. Buenos Aires: Grun Editora, 2005, pp. 237 a 267.

ALBERDI, J. B. Obras completas, T. V, Elementos del Derecho Público Provincial Argentino. Buenos Aires: Imp., Lit. y Enc. de La Tribuna Nacional, 1886, disponible en: http://www.cervantesvirtual.com/nd/ark:/59851/bmcmc964

BIDART CAMPOS, G. Manual de la Constitución reformada, III Tomos. Buenos Aires: Ediar Sociedad Anónima, Editora, Comercial, Industrial y Financiera, 2005.

BIGNE ALCAÑIZ, E., FONT AULET, X. y ANDREU SIMÓ, L. Marketing de destinos turísticos. Análisis y estrategias de desarrollo. Madrid: Editorial ESIC, 2000.

CEBALlOS MARTÍN, Ma. M., PÉREZ GUERRA, R. y DEL BUSTO, E. La legislación o derecho del turismo. Especial referencia a la Comunidad Autónoma de Andalucía, En Congreso Universitario Internacional sobre turismo en Andalucía y norte de Marruecos: 
nuevos retos, nuevas propuestas, Universidad de Málaga, 23 y 24 de Octubre de 2014, Málaga: Facultad de Turismo de la Universidad de Málaga, 2014, pp. 5-15.

CHÁVEZ, J. Turismo y cláusula de prosperidad, En KEMELMAJER DE CARLUCCI, A. Y BENÍTEZ, D. (coords.), Turismo, Derecho y Economía Regional. Santa Fé: Rubinzal Culzoni Editores, 2003, pp. 275-292.

CONSEJO FEDERAL DE INVERSIONES. Encuentro Federal de desarrollo local: el turismo como oportunidad de desarrollo. Conferencias y presentación de casos por expositores de Argentina, América y Europa. Buenos Aires: Consejo Federal de Inversiones, 2011.

DEL BUSTO, E. El rol del derecho en el desarrollo del turismo. En WALLINGRE, N. Y VILLAR, A. (Comps) Gestión de municipios turísticos, instrumentos básicos de acción, Cap. III. Bernal: Editorial Universidad Nacional de Quilmes, 2014, pp. 57-90.

DEL BUSTO, E. Política y legislación turística y hotelera. Bernal: Universidad Nacional de Quilmes, 2007.

FERNÁNDEZ ÁLVAREZ, Competencias en materia turística de la Comunidades Autónomas, Revista Estudios Turísticos $N^{o} 85$, 1985, pp. 37-46

FERNÁNDEZ RAMOS, S. (Dir.) y Raúl Pérez Guerra (Coord.) Manual de Derecho Administrativo del sector turístico, Madrid: Tecnos, 2013.

FERNÁNDEZ RODRÍGUEZ, C. Derecho Administrativo del turismo (Quinta Edición), Barcelona: Marcial Pons, 2010.

FONT I LLOVENT, T. Y VANDELLI, L. (Dirs.). Ordenación jurídico-administrativa del turismo. Barcelona: Atelier, 2018.

GALERA VICTORIA, A. Turismo en F. Balaguer Callejón (Director) Reformas Estatutarias y Distribución de Competencias, Sevilla: Instituto Andaluz de Administración Pública, 2007, 763-774.

GALLARDO CASTILLO, M. J. La distribución constitucional de competencias en materia de turismo y su tratamiento en las Leyes Autonómicas: su promoción y su ordenación. En Documentación Administrativa 259-260, Administración Pública y Turismo. Madrid: Instituto Nacional de la Administración Pública, 2001, pp. 71-93.

GELLI, M. A. Constitución de la Nación Argentina comentada y concordada. Buenos Aires: La Ley, 2006.

GÜIDI, G. Características y alcances de la actividad turística y su regulación. Las leyes nacionales sobre turismo en el Digesto Jurídico Argentino, En BRENA, R. G. (Ed.) Digesto Jurídico Argentino, $1^{a}$ Edición, Buenos Aires, Buenos Aires: La Ley, 2014, pp. 803- 870.

GUILLEN GALINDO, M. La distribución de competencias entre el Estado, las Comunidades Autónomas y las Entidades Locales. Especial referencia a la Comunidad Valenciana, En Actas del I Congreso Universitario de Turismo, celebrado los días 27 a 29 de Octubre de 1998 en Peñíscola, Castellón. Valencia: Tirant lo Blanch, 1999, pp. 43-44

HERNÁNDEZ, A. (H.). La descentralización del poder en el Estado argentino En Memoria del VII Congreso Iberoamericano de Derecho Constitucional. México: Instituto de Investigaciones Jurídicas, Universidad Nacional Autónoma de México, 2002, pp. 211 a 274, disponible en: https://archivos.juridicas.unam.mx/www/bjv/libros/1/348/11.pdf 
HERNÁndeZ, A. (H.) Derecho municipal. Parte General. México: Universidad Nacional Autónoma de México, 2003, disponible http://inafed.gob.mx/work/models/inafed/Resource/322/1/images/Derecho_Municipal_Antoni o_maria hernandez.pdf

HERnÁndeZ, A. M. (Coord.) Derecho Público Provincial. Buenos Aires: Lexis Nexis, 2008.

LUNA, H. D. Lecciones de derecho público provincial y municipal. La Plata: Ediciones Haber, 2014.

MATA IZQUIERDO, J. Turismo, En Derecho público y administración de la Comunidad de Madrid, Madrid: IMAP, pp. 1063-1089.

OBSERVATORIO DE POLÍTICAS PÚBLICAS DEL CUERPO DE ADMINISTRADORES GUBERNAMENTALES. El turismo como política de estado en la República Argentina, Buenos Aires: Jefatura de Gabinete de Ministros.

ORGANIZACIÓN MUNDIAL DEL TURISMO. Guía para administraciones locales: desarrollo turístico sostenible. Madrid: Organización Mundial de Turismo, 1999

PEÑA MIRANDA, D. Los instrumentos legales de la política turística como base para un turismo responsable y sostenible en Latinoamérica; análisis para Colombia, Perú, México y Honduras, En Revista de Análisis Turístico $N^{o} 8,2^{\circ}$ semestre 2009. Asociación Española de Expertos Científicos en Turismo, 2009, pp. 33-43, disponible en: http://www.aecit.org/jornal/index.php/AECIT/article/view/76

PÉREZ GUERRA, R. (Dir.) Derecho de las actividades turísticas, Barcelona: Fundación Universidad Oberta de Cataluña UOC, 2003.

PÉREZ GUERRA R. Y CEBALLOS MARTÍN, Mª M. La configuración del Derecho del Turismo Autonómico Español en el ordenamiento jurídico administrativo-constitucional En Revista Aragonesa de Administración Pública, núm. 35, Zaragoza, 2009, pp. 455-515.

PÉREZ GUERRA, R. Y CEBALLOS MARTÍN, Ma. M. Las competencias de la comunidad autónoma de Andalucía en materia de turismo. En FERNÁNDEZ RAMOS, S. (coord.) Estudios sobre derecho andaluz del turismo, Sevilla: Consejería de Turismo, Comercio y Deporte, de la Junta de Andalucía, 2008, pp. 23 a 64.

PÉREZ GUERRA, R. y CEBALLOS MARTÍN, Ma.M. Hacia la configuración del Estatuto del Municipio Turístico estudio del proyecto de Derecho de Municipio Turístico de Andalucía, Congreso de la Asociación Española de Expertos Científicos en Turismo, Ceuta, 2002, pp. 369 a 382.

QUIROGA LAVIÉ, H., BENEDETTI, M. A. Y CENICASELAYA, M. Derecho Constitucional Argentino, 2da. Edición. Santa Fé: Rubinzal-Culzoni. 2009.

RODRÍGUEZ ARANA MUÑOZ, J. La distribución de competencias en materia de turismo en Documentación administrativa 259-260, Enero-Agosto de 2001 Administración Pública y Turismo, Instituto Nacional de la Administración Pública, Madrid, (2001), p. 27- 38.

ROSATTI, H. Tratado de derecho municipal, II Tomos. Buenos Aires: Rubinzal - Culzioni Editores, 2006.

SAGÜES, N. P. Manual de derecho Constitucional, 2da. Edición. Buenos Aires: Editorial Astrea, 2012. 
SCHENKEL E. Política Turística y turismo social. Buenos Aires: Ediciones CICCUS, 2017.

SECTUR. Ley Nacional de Turismo 25997. El comienzo del cambio. Buenos Aires: Secretaría de Turismo de la Nación, 2005.

SPOTA, A. Distribución de competencias en el Estado federal, ente éste y las provincias. El tema y sus nuevos aspectos frente a los procesos de integración y reajustes constitucionales", En Revista Jurídica La Ley 1992-D. Buenos Aires: La Ley, 1992, pp. 890-906.

SPOTA, A. Aproximación a la autonomía provincial a través de la jurisprudencia de la Corte Suprema de Justicia de la Nación", En Anales de la Academia Nacional de Ciencias Morales y Políticas, Tomo XXXV, 2008, disponible en https://www.ancmyp.org.ar/user/FILES/Spota.pdf.

TALE, C. Contrato de viaje: Responsabilidad de las empresas de turismo por incumplimiento y por daños al viajero. Buenos Aires: José Luis Depalma Editor.

VERA, F. (Coordinador), LÓPEZ PALOMEQUE F., MARCHENA M.J., ANTÓN, S. Análisis Territorial del Turismo. Una nueva geografía del turismo. Barcelona: Editorial Ariel S.A., 1997.

WALLINGRE, N. Definición y parámetros de identificación de municipios turísticos En WALLINGRE, N. y VILLAR, A. (comps) Gestión de municipios turísticos, instrumentos básicos de acción, Cap. I, Bernal, Editorial Universidad Nacional de Quilmes, 2014, pp. 1740.

ZAVALÍA, C. Lecciones de Derecho Público Provincial, $2^{a}$ edición, Buenos Aires: Talleres Gráficos Argentinos L. J. Rosso, 1937.

ZIULU, G. Derecho Constitucional. Buenos Aires, Buenos Aires: Ediciones Depalma, 1996.

ZUCCHERINO, R. M. Derecho público provincial y municipal, II Tomos. La Plata: Editorial Lex, 1976. 